\title{
RESOLUSI KONFLIK TENURIAL PEMANFAATAN KAWASAN HUTAN DI HUTAN LINDUNG RIMBO DONOK KABUPATEN KEPAHIYANG \\ (The Tenurial Conflicts Resolution of Utilization of Forest Areas in Protected Forests Rimbo Donok Kepahiang District)
}

\author{
Gunggung Senoaji ${ }^{1^{*}}$, Muhamad Fajrin Hidayat ${ }^{1}$, dan Iskandar ${ }^{2}$ \\ ${ }^{1}$ Jurusan Kehutanan Universitas Bengkulu, Jl. Raya Kandang Limun Bengkulu, 38173. \\ ${ }^{2}$ Fakultas Hukum Universitas Bengkulu, Jl. Raya Kandang Limun Bengkulu, 38173.
}

*Penulis korespondensi. Tel: 081377986131. Email: senoaji1211@gmail.com.

Diterima: 23 Oktober 2017

Disetujui: 12 September 2018

\begin{abstract}
Abstrak
Hutan Lindung Rimbo Donok memiliki luas 377,99 ha, terletak di Kabupaten Kepahiyang Provinsi Bengkulu. Fungsi utama dari hutan lindung ini adalah sebagai sistem penyangga kehidupan untuk mengatur tata air, mencegah banjir dan erosi, dan menjaga kesuburan tanah. Seharusnya, tutupan vegetasi kawasan hutan ini berupa hutan primer. Namun fakta di lapangan, seluruh kawasan hutan ini telah berubah menjadi lahan pertanian. Penelitian ini bertujuan untuk mengetahui karakteristik masyarakat penggarap lahan di kawasan hutan lindung Rimbo Donok dan mencari alternatif resolusi konflik yang terjadi. Metode penelitian yang digunakan adalah teknik pemetaan, pengamatan lapangan dan wawancara. Hasil penelitian menunjukkan bahwa penggunaan lahan di hutan lindung Rimbo Donok seluruhnya berupa lahan pertanian, yang digarap masyarakat secara tidak sah dengan menanam kopi dan tanaman pertanian lainnya. Rata-rata luas lahan garapan untuk setiap kepala keluarga sekitar 1,33 ha. Resolusi konflik pemanfaatan hutan ini harus bisa mengakomodir fungsi sosial ekonomi dan fungsi perlindungan lingkungan. Upaya legalisasi pemanfatan hutan harus dilakukan dengan berbagai skema seperti : hutan kemasyarakatan, hutan desa, atau kemitraan. Pengolahan lahannya dapat menggunakan sistem agroforestry.
\end{abstract}

Kata kunci: Agroforestry, Hutan Lindung, Konflik Tenurial.

\section{Abstract}

Rimbo Donok Protected Forest covers 377.99 ha area, located in Kepahiyang District, Bengkulu Province, Indonesia. The main function of protected forest is to protect life buffer system. Therefore, the land use must be forest. In Rimbo Donok Protected Forest, there has been a change of land use from forest land to crop land. There has been tenurial conflicts in the utilization of forest area. The objective of this study was to determine the characteristics of tenants in Rimbo Donok protected forest area and choose alternatives to resolve tenurial conflicts. The data of uses were collected through mapping techniques, field observation, and interview. The results showed that land use of Rimbo Donok Protected Forest in 2016 is entirely crop land. All of this protected forest have been illegaly occupied by people. These people are planting coffe and other agricultural plants in the area. The average land area of head family is 1.33 ha. This conflict resolution of forest utilization should be able to accommodate the socio-economic function and environmental protection function. Efforts to legalize the utilization of forests should be carried out under various schemes such as: community forest, village forest, or partnership. the agroforestry system can be selected as its land management system.

Keywords: agroforestry, forest protected, tenurial conflicts.

\section{PENDAHULUAN}

Hutan merupakan sumber daya alam karunia Tuhan yang maha kuasa dengan fungsi utamanya sebagai pengendali bagi perlindungan ekosistem bumi (Simon, 2001). Hutan berperan penting dalam mengatur tata air (Asdak, 2004; Ulya dkk, 2014), gudang plasma nutfah dan menjaga kesuburan tanah (Indriyanto, 2006), dan menyerap karbon dioksida di udara (Wibowo, 2013). Selain untuk perlindungan lingkungan, hutan juga berfungsi sebagai sumber ekonomi bagi manusia, seperti sumber pangan (Dwiprabowo dkk, 2011), penghasil kayu (Rahmat, 2011; Hidayat, 2012), barang tambang (Zubayr, dkk, 2014), dan ekowisata (Supyan, 2011).

Untuk mengakomodir fungsi perlindungan lingkungan dan fungsi ekonomi dari hutan secara seimbang, pemerintah membuat kebijakan pengklasifikasian kawasan hutan menjadi hutan konservasi, hutan lindung, dan hutan produksi (Anonimus, 1999). Hutan lindung merupakan kawasan hutan yang mempunyai fungsi pokok sebagai perlindungan sistem penyangga kehidupan untuk mengatur tata air, mencegah banjir, mengendalikan erosi, mencegah intrusi air laut, dan memelihara kesuburan tanah. Salah satu kawasan hutan lindung yang berada di Provinsi Bengkulu 
adalah Hutan Lindung Rimbo Donok (Register 8) yang terletak di Kabupaten Kepahiyang.

Hutan Lindung Rimbo Donok telah ditetapkan sebagai kawasan hutan lindung berdasarkan Surat Keputusan Menteri Kehutanan No. 3982/MenhutVII/KUH/2014 tanggal 23 Mei 2014 dengan luas kawasan 377,99 ha. Penetapan kawasan Hutan Lindung Rimbo Donok ini ditujukan sebagai sistem penyangga kehidupan melalui pengatur tata air, penyerap karbon, dan mencegah banjir-longsor bagi masyarakat yang tinggal di sekitar daerah aliran sungai Hulu Musi, Kabupaten Kepahiyang. Idealnya kawasan hutan lindung ini tutupan vegetasinya berupa hutan primer. Namun kenyataan di lapangan, seluruh tutupan vegetasinya telah berubah menjadi lahan pertanian kering campur.

Fungsi hutan lindung sebagai sistem penyangga kehidupan sudah tidak berjalan dengan baik. Perubahan tutupan vegetasi di hutan lindung mulai terjadi ketika kepemilikan lahan pertanian masyarakat mulai menyempit. Pertambahan penduduk yang terus menerus menyebabkan tekanan masyarakat terhadap kawasan hutan semakin tinggi, sedangkan penegakan hukum bagi para perambah hutan belum berjalan maksimal (Kaimuddin, 2008). Ketergantungan masyarakat ke dalam kawasan hutan menjadi tinggi (Yusran dan Abdulah, 2007). Ketergantungan masyarakat hutan dalam memanfaatkan hutan tidak seluruhnya dipayungi oleh aturan hukum yang ada. Masih banyak masyarakat yang mengolah lahan hutan secara illegal. Klaim terhadap lahan garapan sebagai tanah adat yang merupakan warisan leluhur dijadikan alasan untuk memanfatkan kawasan hutan. Tindakan yang dilakukan masyarakat dengan memanfaatkan hutan lindung sebagai lahan pertanian secara tidak sah merupakan tindakan penyerobotan kawasan hutan, sehingga menimbulkan konflik dengan pengelola kawasan hutan (Dassir, 2008).

Ketergantungan dan tekanan yang tinggi masyarakat terhadap kawasan hutan, membuat pemerintah mencari berbagai skema pemanfaatan hutan oleh masyarakat. Kementerian kehutanan telah melakukan revitalisasi dalam pengelolaan kawasan hutan melalui program sosial forestry dengan berbagai pola pemberdayaan masyarakat (Heryatna, dkk., 2015). Prinsip dasar dari skema pemanfaatan hutan oleh masyarakat ini adalah mengakomodir masyarakat sekitar hutan untuk mengolah lahan hutan dengan menerapkan sistem agroforestry, yang mengkombinasikan tanaman kehutanan dengan tanaman pertnaian. Pengolahan lahan dengan sistem agroforestry dapat mempertahankan jumlah dan keragaman produksi lahan, sehingga berpotensi memberikan manfaat sosial, ekonomi, dan lingkungan (Hairiah, dkk.,
2004). Manfaat dari sisi ekonomi adalah sebagai salah satu sumber pendapatan masyarakat; sedangkan dari sisi ekologi dapat meningkatkan kesuburan lahan dan perlindungan lingkungan (Senoaji, 2012).

Pemanfaatan kawasan hutan oleh masyarakat untuk berbagai kepentingan harus mendapat ijin dari pemerintah karena hutan merupakan public goods yang mempunyai multi fungsi. Pemanfaatan lahan hutan tanpa ijin merupakan pelanggaran hukum sesuai dengan pasal 50 Undang-Undang No. 41 tahun 1999 tentang kehutanan. Kawasan Hutan Lindung Rimbo Donok telah digarap oleh masyarakat menjadi lahan pertanian. Penelitian ini bertujuan untuk mengetahui kondisi kawasan Hutan Lindung Rimbo Donok, karakteristik masyarakat penggarapnya, status lahan garapannya, dan alternatif penyelesaian konflik yang terjadi.

\section{METODE PENELITIAN}

\section{Waktu dan Lokasi}

Penelitian ini dilakukan di Kawasan Hutan Lindung Rimbo Donok, Kabupaten Kepahiyang, Provinsi Bengkulu. Penelitian dilaksanakan selama 3 bulan yakni pada periode bulan April-Juni 2017.

\section{Prosedur}

Pengumpulan data dilakukan dengan teknik pemetaan, wawancara dan pengamatan lapangan. Pemetaan dilakukan untuk mengetahui kondisi penggunaan lahan aktual di kawasan hutan lindung ini, dengan menggunakan Peta Penggunaan Lahan Tahun 2016 (Gambar 1) yang diterbitkan oleh Badan Planologi Kementerian Lingkungan Hidup dan Kehutanan Republik Indonesia.

Teknik wawancara dilakukan terhadap masyarakat yang sebagai responden penelitian. Respondennya adalah masyarakat yang menggarap kawasan hutan. Pemilihan responden dilakukan metode insidental sampling di lokasi penelitian, yakni pemilihan sampel dengan memilih para penggarap lahan yang secara kebetulan ditemui di lokasi penelitian dan dipandang sesuai sebagai sumber data. Kriteria responden yang terpilih adalah masyarakat dewasa, memiliki lahan garapan di Hutan Lindung Rimbo Donok, serta sehat jasmani dan rohani. Pengamatan lapangan dilakukan pada lahan garapan yang dikelola oleh para responden, meliputi : letak dan luas lahan garapan, jenis tanaman yang tumbuh, dan pola tanamnya. Jumlah respondennya 44 orang, dengan menggunakan rumus Slovin (Nazir, 2009).

$$
\mathrm{n}=(0.25)\left(\frac{Z_{\alpha / 2}}{\varepsilon}\right)^{2}
$$

di mana : 
$\mathrm{n} \quad=$ jumlah responden

$\mathrm{Z} \alpha / 2=$ nilai yang didapat dari tabel normal atas tingkat keyakinan $=1,96$

$\varepsilon=$ kesalahan penarikan $/$ margin of error $=$ $15 \%$

Data dan informasi yang dikumpulkan dianalisis dengan analisis sistem informasi geografis (SIG) dan analisis deskriptif kualitatifkuantitatif. Data yang dianalisis secara deskriptif kuantitatif-kualitatif meliputi kondisi sosial dan ekonomi, letak dan luas lahan garapan, status lahan garapan, pola pemanfaatan lahan, dan jenis tanaman di lahan garapan.

\section{HASIL DAN PEMBAHASAN}

\section{Kondisi Hutan Lindung Rimbo Donok}

Hasil analisis citra satelit terhadap tutupan vegetasi yang dirilis oleh Kementerian Lingkungan Hidup dan Kehutanan tahun 2017, menunjukkan bahwa tutupan vegetasi Hutan Lindung Rimbo Donok, seluruhnya berupa lahan pertanian kering campur. Ini berarti seluruh kawasan hutan ini telah berubah menjadi lahan garapan masyarakat. Fenomena seperti ini banyak terjadi pada kawasan hutan di Provinsi Bengkulu, baik di hutan lindung ataupun hutan produksi. Menurut Senoaji (2009), cukup banyak kawasan hutan lindung yang telah dimanfaatkan masyarakat untuk diluar fungsi perlindungan seperti untuk lahan kebun, ladang, pemukiman, dan sawah. Perambahan kawasan hutan merupakan hal yang biasa terjadi pada wilayah yang berbatasan dengan kawasan hutan dan berpotensi tetap berlanjut karena penegakan hukum kasusnya belum maksimal (Kaimuddin, 2008). Di lain pihak, kontribusi pendapatan masyarakat sekitar hutan dari dalam kawasan hutan lindung mencapai 52,5 \% (Senoaji, 2009), yang terkait dengan usaha tani masyarakat di dalam kawasan hutan (Supratman, 2007).

Dari Gambar 1, terlihat bahwa pengunaan lahan di kawasan Hutan Lindung Rimbo Donok, seluruhnya berupa pertanian lahan kering campur. Kawasan hutan akan berfungsi optimal sebagai sarana perlindungan lingkungan jika bervegetasi pohon seperti hutan alam yang memiliki strata tajuk dan perakaran yang bertingkat (Simon, 2007). Mengingat kawasan hutan ini fungsinya sebagai hutan lindung, perlu dilakukan upaya untuk mengembalikan fungsi tersebut dengan tetap memperhatikan masyarakat penggarap yang mengelolanya. Kebijakan pemerintah tentang pengelolaan hutan lindung dan hutan produksi mengarah pada pemberdayaan masyarakat sekitar hutan dengan tetap memperhatikan fungsi utamanya sebagai perlindungan lingkungan dan atau penyedia hasil hutan.

Pada kawasan hutan lindung ini, seluruh petani penggarap menanam kopi (Coffea canephora) sebagai tanaman pokoknya. Jenis tanaman sampingan lainnya yang ditanam para petani penggarap untuk pemenuhan kebutuhan sehari-hari di antaranya adalah cabe (Capsium frutesces), pepaya (Carica papaya), buncis (Phaseolus

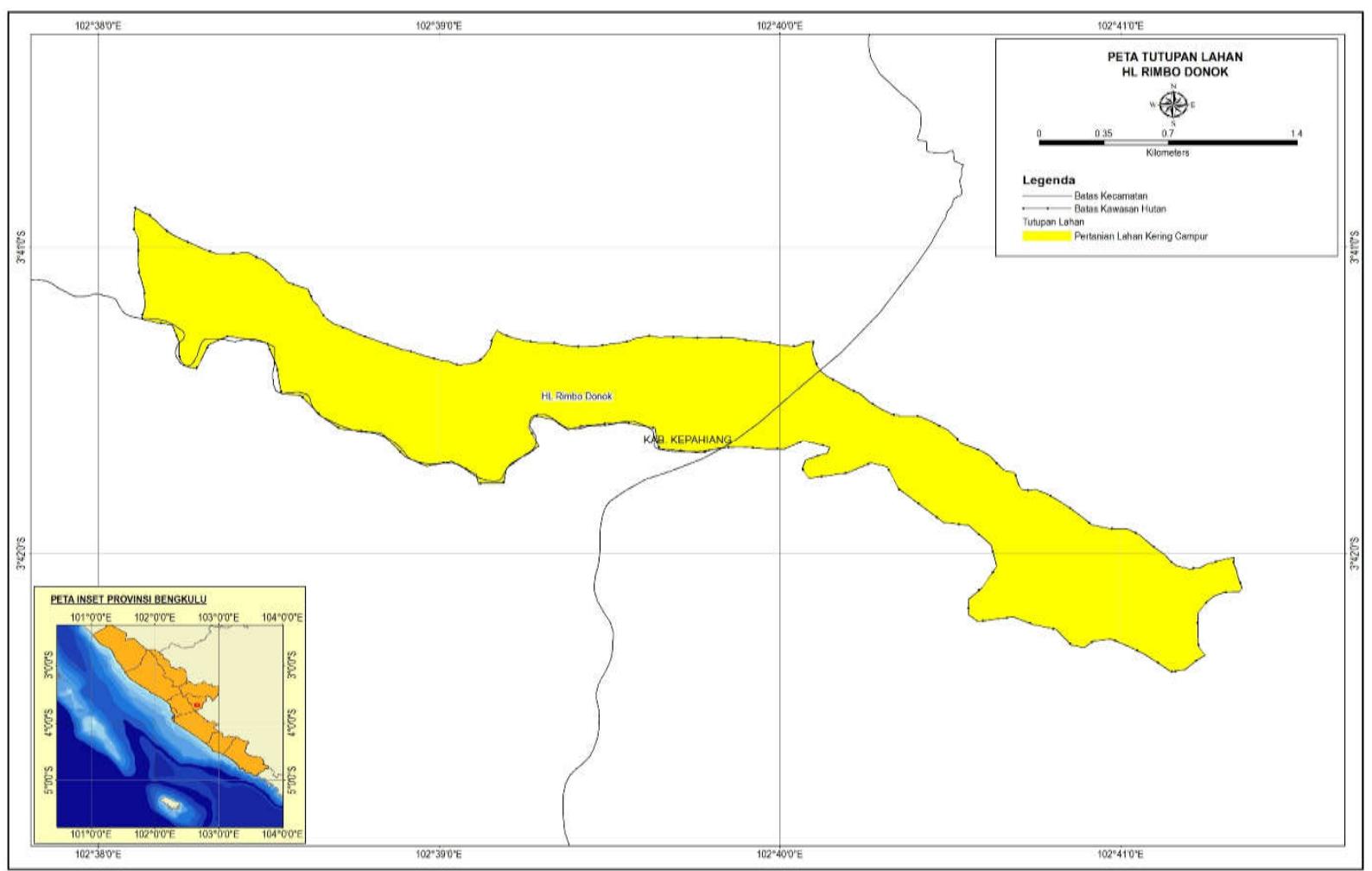

Gambar 1. Peta Penggunaan Lahan di Kawasan Hutan Lindung Rimbo Donok. 
vulgaris), jahe (Zingiber officinale), kacang panjang (Vigna sinensis), lengkuas (Languasa galanga), tomat (Solanum lycopersicum), lada (Piper nigrum), serai (Cymbopogan citratus), pisang (Musa spp), tebu (Saccharum officinarum), terung (Sonamum melongena), labu kuning (Cucurbita moschata) nanas (Ananas comosus), kunyit (Curcuma longa), daun bawang (Allium fistulosum), ubi kayu (Manihot esculenta), dan buah naga (Hylocereus undatus). Pada beberapa lahan garapan petani, ditemukan beberapa jenis pohon penghasil buah atau sebagai pelindung seperti alpokat (Persea gratissima), lamtoro (Leucaena leucochepala), durian (Durio spp), aren (Arenga pinata), kelapa (Cocos nucifera), mangga (Mangifira indica), merambung (Vernonia arborea), bambang lanang (Madhuca aspera), kapuk (Ceiba pentandra), bambu (Bambuseae sp.), petai (Parkia speciosa), dan kayu res (Gliricidia sepium).

Kawasan hutan yang sudah terdesak oleh perkebunan kopi, hanya menyisakan sedikit tegakan pepohonan sebagai penghasil kayu bahan bangunan (Hidayat, 2012). Kawasan Hutan Lindung Rimbo Donok ini, seakan-akan telah berubah menjadi lahan penghasil pangan bagi masyarakat dan menjadi rumah kedua bagi mereka. Para petani penggarap membangun "pondok kebun" dengan tempat penjemuran kopi di setiap lahan garapannya. Pada hari-hari di luar musim panen, para petani penggarap akan pulang-pergi ke desanya dalam mengelola lahan garapannya. Pada musim panen kopi, mereka akan tinggal di "pondok kebunnya" sekitar 3-4 bulan dalam setahun. Mereka akan kembali ke desanya jika panen kopi telah selesai dengan membawa hasil panen kopi yang sudah kering dan siap jual. Perilaku masyarakat penggarap dalam mengelola hutan lindung ini telah dianggap menjadi hal yang lumrah, padahal bertentangan dengan regulasi yang berlaku.
Perilaku seperti ini dipengaruhi oleh pengalamanan individu, motivasi, norma subyektif, dan keyakinannya (Azwar, 2010); namun berbeda dengan perilaku masyarakat Baduy dalam mengelola lahan garapannya yang dilakukan secara legal (Senoaji, 2011).

\section{Karakteristik Masyarakat Penggarap Kawasan Hutan Lindung Rimbo Donok Tingkat Pendidikan}

Tingkat pendidikan mempengaruhi seseorang dalam kemampuan berpikir (Adhawati, 1997). Pendidikan dipandang tidak hanya dapat menambah pengetahuan tetapi juga dapat meningkatkan keterampilan tenaga kerja sehingga akan meningkatkan produktivitas. Pada Tabel 1 disajikan data karakteristik petani penggarap berdasarkan tingkat pendidikan.

Petani penggarap lahan kawasan Hutan Lindung Rimbo Donok sebagian besar berpendidikan Sekolah Dasar (38,64\%) dan SLTP (34,09\%). Angka ini memberikan indikasi bahwa tingkat pendidikan para petani penggarap ini masih rendah. Inovasi baru tentang sesuatu hal akan relatif lebih sulit dipahami oleh mereka.

\section{Luas Lahan Garapan}

Luas lahan garapan merupakan modal petani dalam berusaha tani. Pendapatan petani dari usaha taninya salah satunya ditentukan oleh luas lahan garapannya, karena dapat mempengaruhi produksi per satuan luas. Purwanti (1997) mengelompokkan luas lahan garapan menjadi : "sedikit" jika luasnya kurang dari 1 ha, "sedang" jika luasnya 1-3 ha, dan "banyak" jika luasnya lebih dari 3 ha.

Dari Tabel 2, diketahui bahwa sebagian besar $(97,73 \%)$ luas lahan garapan petani termasuk dalam katagori sedang (1-3 ha). Hanya 2,27 \% yang memiliki luas lahan garapan kurang dari $1 \mathrm{Ha}$. Rata-rata luas lahan garapan di dalam hutan lindung

Tabel 1. Karakteristik petani penggarap berdasarkan tingkat pendidikan.

\begin{tabular}{llcc}
\hline No & \multicolumn{1}{c}{ Tingkat pendidikan } & Jumlah responden & Persentase (\%) \\
\hline 1. & Tidak Sekolah & 1 & 2,27 \\
2. & SD & 17 & 38,64 \\
3. & SLTP & 15 & 34,09 \\
4. & SLTA & 10 & 22,73 \\
5. & Perguruan Tinggi & 1 & 2,27 \\
\hline Jumlah & & 44 & 100 \\
\hline
\end{tabular}

Sumber : Olahan data primer, 2017

Tabel 2. Karakteristik responden berdasarkan luas lahan garapan.

\begin{tabular}{llrc}
\hline No & \multicolumn{1}{c}{ Luas lahan garapan } & Jumlah responden & Persentase (\%) \\
\hline 1. & Sedikit (<1 hektar ) & 1 & 2,27 \\
2. & Sedang (1-3 hektar) & 43 & 97,73 \\
3. & Banyak ( $>3$ hektar) & 0 & 0 \\
\hline & Jumlah & 44 & 100 \\
\hline
\end{tabular}

Sumber : Olahan data primer, 2017 
Tabel 3. Karakteristik petani penggarap berdasarkan cara memperoleh lahan garapan.

\begin{tabular}{|c|c|c|c|}
\hline No & Cara memperoleh lahan garapan & Jumlah responden & Persentase $(\%)$ \\
\hline 1. & Menyewa & 6 & 13,64 \\
\hline 2. & Membuka lahan & 1 & 2,27 \\
\hline 3. & Warisan & 12 & 27,27 \\
\hline 4. & Membeli & 25 & 56,82 \\
\hline Jumlah & & 44 & 100 \\
\hline \multicolumn{4}{|c|}{ Sumber : Olahan data primer, 2017} \\
\hline No & Desa dan status & Jumlah responden & Persentase $(\%)$ \\
\hline 1. & Desa sekitar hutan & 32 & 72,72 \\
\hline 2. & Desa bukan sekitar hutan & 12 & 27,28 \\
\hline Jumlah & & 44 & 100 \\
\hline
\end{tabular}

Sumber : Olahan data primer, 2017

ini untuk setiap kepala keluarga adalah 1,33 ha.

Dengan luas kawasan hutan sekitar 378 ha, diperkirakan terdapat 280 kepala keluarga yang menggarap. Masyarakat penggarap yang memiliki lahan pertanian sebagai hak milik (di luar kawasan hutan) hanya $4,54 \%$; selebihnya $(95,46 \%)$ tidak memiliki lahan milik, sehingga sumber pendapatannya sangat tergantung kepada lahan garapan yang berada di dalam kawasan hutan lindung ini.

\section{Cara Mendapatkan Lahan Garapan}

Lahan garapan yang diolah petani merupakan kawasan Hutan Lindung Rimbo Donok. Secara yuridis, lahan ini merupakan milik negara yang kewenangan pengelolaannya diserahkan kepada pemerintah Provinsi Bengkulu. Berdasarkan regulasi yang berlaku dalam Undang-Undang No. 41 tahun 1999 pasal 50 ayat 3 butir (a), disebutkan bahwa setiap orang dilarang mengerjakan dan atau menggunakan dan atau menduduki kawasan hutan secara tidak sah. Fakta di lapangan, hampir seluruh kawasan hutan lindung ini, telah dimanfaatkan oleh masyarakat sebagai lahan pertanian. Masyarakat penggarap menganggap bahwa lahan garapannya adalah milik sah mereka yang diperolehnya melalui berbagai cara., yakni mulai dari membuka lahan sendiri, membeli, warisan dari orang tua dan menyewa dari pemiliknya.

Dari Tabel 3, dijelaskan bahwa sebanyak $13,64 \%$ petani penggarap memperoleh lahan garapannya dengan cara menyewa kepada masyarakat yang dianggap memiliki lahan garapan; $27,27 \%$ memperoleh lahan garapannya dari pemberian atau warisan orang tuanya; $56,82 \%$ memperoleh lahan garapannya dengan cara membeli kepada pemilik sebelumnya; dan hanya 2,27\% memperoleh lahan garapannya dengan membuka lahan sendiri. Di tingkat masyarakat telah terjadi kesepakatan di antara mereka tentang status kepemilikan lahan garapan di dalam kawasan hutan.

\section{Domisili Petani Penggarap}

Pada tabel 4 disajikan karakteristik petani penggarap berdasarkan lokasi domisili. Tampak bahwa program pemerintah tentang pemberdayaan masyarakat sekitar hutan, hanya ditujukan untuk masyarakat yang berdomisili di desa-desa sekitar hutan. Desa-desa yang berada di sekitar Hutan Lindung Rimbo Donok adalah Talang Karet, Peraduan Binjang, Tebing Penyamun, Penanjung Panjang dan Air Pauh.

\section{Resolusi Konflik Tenurial Pemanfaatan Kawasan Hutan}

Konflik adalah benturan yang terjadi antara dua pihak atau lebih yang disebabkan karena adanya perbedaan kondisi sosial budaya, nilai, status, dan kekuasaan (Fuad dan Maskanah, 2000); atau persepsi mengenai perbedaan kepentingan (Pruitt dan Rubin, 2009); sedangkan konflik tenurial adalah konflik dalam penguasaan lahan dan sumber daya alam (Sylviani dan Hakim, 2014). Konfik tenurial pada kawasan hutan berarti terjadi benturan dalam penguasaan lahan dan sumber daya dalam kawasan hutan, seperti konflik pengelola hutan dengan masyarakat yang memanfaatkan kawasan hutan untuk areal pemukiman, jalan, ladang dan kebun (Dassir, 2008). Konflik penguasaan tanah muncul dari persepsi dan interpretasi yang berbeda yang dimiliki antar pihak terhadap hak mereka atas tanah dan sumber daya hutan (Safitri dkk, 2011).

Konflik dalam pengelolaan sumberdaya hutan dapat disebabkan oleh keterbatasan sumberdaya alam dan kebutuhan yang selalu meningkat, bertambahnya jumlah penduduk memunculkan berbagai kepentingan yang berbeda atas sumberdaya yang sama, dan perubahan kondisi sosial, budaya, lingkungan hidup, ekonomi, hukum dan politik menciptakan kepentingan-kepentingan dan kebutuhan- kebutuhan baru terhadap sumberdaya hutan (Fuad dan Maskanah, 2000). Konflik tenurial ini digambarkan sebagai fenomena 
yang terjadi akibat dominasi pemerintah sebagai pemegang kekuasaan yang melahirkan perlawanan masyarakat. Kekuasaan pemerintah sebagai representasi negara melalui kebijakan dan penerapannnya serta implikasinya dalam pengelolaan hutan seringkali berlawanan dengan peran dan kepentingan masyarakat lokal yang tinggal di sekitar kawasan hutan (Maring, 2013).

Konflik tenurial pada kawasan hutan melibatkan berbagai pihak yang berkepentingan, yakni pemerintah, masyarakat lokal, dan lembaga swadaya masyarakat. Pemerintah berkepentingan mengamankan hutan sebagai kawasan hutan negara, masyarakat berkepentingan secara sosial dan ekonomi atas sumberdaya hutan, untuk memenuhi kebutuhan hidupnya dan lembaga swadaya masyarakat berkepentingan membela hakhak masyarakat atas sumberdaya hutan.

Konflik pemerintah dengan masyarakat sekitar hutan sering terjadi karena selama ini pembangunan kehutanan belum memperhatikan kondisi sosial ekonomi budaya masyarakat. Ketertinggalan dari segi ekonomi menyebabkan timbul sikap resistensi dari masyarakat terhadap pihak luar yang mengelola hutan. Sikap inilah yang merupakan potensi laten terjadinya konflik dalam pengelolaan sumberdaya hutan (Nugraha, 1999). Oleh karena itu, Darusman (1993) menyatakan bahwa masyarakat di dalam dan sekitar hutan harus lebih diperhatikan dalam pembangunan sektor kehutanan, karena mereka adalah bagian atau unsur dari ekosistem hutan yang saling tergantung satu sama lainnya.

Menurut Maring (2013), keberadaan hutan sebagai sumberdaya alam tidak bisa dijauhkan dari akses dan peran masyarakat lokal yang tinggal di dalam dan di sekitar hutan. Ironinya, kebijakan pengelolaan hutan di Indonesia memberikan akses yang kecil kepada masyarakat yang tinggal di dalam dan sekitar kawasan hutan. Akibat kebijakan pengelolaan hutan yang tidak memperhatikan dan mengadopsi sistem pengelolaan hutan yang dikembangkan masyarakat adalah terjadinya kemunduran pengelolaan hutan oleh masyarakat lokal. Kemunduran pengelolaan hutan juga merupakan akibat dari berbagai distorsi yang ditunjukkan aparat kehutanan dan pengusaha hutan; yang akhirnya masyarakat lokal ikut berperan juga dalam pemanfaatan lahan hutannya secara illegal.

Hasil penelitian di kawasan Hutan Lindung Rimbo Donok, menunjukkan bahwa seluruh petani penggarap tidak memiliki ijin pemanfaatan hutan. Petani penggarap secara illegal memanfaatkan kawasan hutan sebagai lahan garapan pertanian. Lahan garapan diperoleh dengan cara membuka sendiri, menyewa, membeli, ataupun warisan dari orang tuanya. Motivasinya menggarap kawasan hutan ini adalah untuk kepentingan ekonomi, yakni memenuhi kebutuhan hidupnya sehari-hari. Hutan telah menjadi sumber pangan dan sumber pendapatan bagi masyarakat penggarapnya. Kondisi kawasan hutan lindung seperti ini tidak lagi berfungsi sebagai perlindungan lingkungan, padahal penetapan hutan lindung diutamakan untuk menjaga sistem penyangga kehidupan, seperti mencegah banjir, erosi, dan menjaga kesuburan tanah.

Pemerintah harus segera menerapkan kebijakan yang dapat meningkatkan fungsi hutan lindung sebagai perlindungan lingkungan, namun dengan tetap mengakomodir keberadaan masyarakat di hutan lindung ini. Tindakan penggusuran dan pengusiran para petani penggarap dari dalam hutan lindung, bukanlah solusi yang tepat, karena mereka menggantungkan hidupnya dari kawasan hutan. Legalitas para penggarap lahan hutan perlu dilakukan untuk keberlanjutan pemanfaatannya dan meningkatkan fungsi lindung.

Berbagai kebijakan pemerintah yang berhubungan dengan pemberdayaan masyarakat sekitar hutan yang dapat dipakai untuk legalisasi pemanfaatan kawasan hutan di Hutan Lindung Rimbo Donok adalah peraturan hutan kemasyarakatan (Permenhut No. 88 tahun 2014), peraturan hutan desa (Permenhut No. 89 tahun 2014), dan peraturan kemitraan kehutanan (Permenhut No. 39 tahun 2013). Prinsip dasar dari skema-skema pemberdayaan masyarakat tersebut adalah mengijinkan masyarakat sekitar hutan untuk memanfaatkan lahan hutan6 melalui pengaturan pola dan jenis tanaman. Para petani penggarap diharuskan menanam tanaman kehutanan (pohon) di samping tanaman pertanian. Sistem agroforestri merupakan pilihan yang tepat untuk menentukan pola tanamnya.

Agroforestry merupakan manajemen pemanfaatan lahan secara optimal dan lestari dengan cara mengkombinasikan kegiatan kehutanan dan pertanian pada unit pengelolaan lahan yang sama dengan memperhatikan kondisi lingkungan fisik, sosial, ekonomi, dan budaya masyarakat (Anonimus, 1992). Teknik agroforestry akan menekankan penggunaan jenis-jenis pohon serbaguna dan menentukan asosiasi antara jenisjenis vegetasi yang ditanam. Dalam konteks agroforestry, pohon serbaguna mengandung pengertian semua pohon atau semak yang digunakan atau dikelola untuk lebih dari satu kegunaan produk atau jasa; yang penekanannya pada aspek ekonomis dan ekologis. Saat ini agroforestry diyakini secara luas mempunyai potensi besar sebagai alternatif pengelolaan lahan 
yang utama untuk konservasi tanah dan juga pemeliharaan kesuburan dan produktivitas lahan di daerah tropis. Keyakinan ini didasarkan pada hipotesa bahwa pohon dan vegetasi besar lainnya dapat meningkatkan kesuburan tanah di bawahnya (Nair, 1993). Sistem agroforestry di kawasan hutan akan meningkatkan kualitas perlindungan lingkungan, memperbaiki produktivitas lahan, dan meningkatkan kesejahteraan petani penggarap (Triwanto dkk. 2012), serta sesuai dilakukan pada lahan kritis pada berbagai kondisi landscape (Bukhari dan Febryano, 2009) seperti halnya di kawasan hutan lindung.

\section{KESIMPULAN}

Hutan Lindung Rimbo Donok telah ditetapkan oleh pemerintah sebagai dengan fungsi utama sebagai sistem penyangga kehidupan melalui pengatur tata air, penyerap karbon, dan mencegah banjir-longsor bagi masyarakat yang tinggal di sekitar daerah aliran sungai Hulu Musi, Kabupaten Kepahiyang. Namun, tutupan vegetasi hutan lindung ini telah berubah nenjadi lahan pertanian kering campur akibat kegiatan pembukaan lahan hutan oleh masyarakat sekitar yang sebagian besar tidak memiliki lahan hak milik. Kawasan hutan lindung ini telah menjadi sumber pangan dan pendapatan bagi masyarakat penggarapnya. Telah terjadi konflik tenurial antara masyarakat dengan pengelola kawasan hutan.

Pengusiran dan penggusuran masyarakat penggarap dari dalam kawasan hutan lindung hanya akan menimbulkan masalah sosial baru, yakni meningkatnya kemiskinan bagi masyarakat sekitar hutan. Pemberdayaan masyarakat sekitar hutan melalui berbagai skema, seperti hutan kemasyarakatan, hutan desa, atau kemitraan, diharapkan dapat menjadi resolusi konflik tenurial ini. Skema pemberdayaan masyarakat ini akan melegalkan kegiatan petani penggarap dan dapat menciptakan ekosistem lahan garapannya menyerupai ekosistem hutan, melalui penerapan sistem agroforestry yang menggabungkan tanaman pertanian dengan tanaman kehutanan.

\section{UCAPAN TERIMAKASIH}

Penulis mengucapkan terima kasih kepada Direktorat Jenderal Penguatan Riset dan Pengembangan Kementerian Riset, Teknologi, dan Pendidikan Tinggi, Kementerian Ristek Dikti Republik Indonesia, yang telah membiayai penelitian ini dalam skema Penelitian Unggulan Perguruan Tinggi (PUPT) tahun 2017, sesuai dengan kontrak penelitian Nomor :
061/SP2H/LT/DRPM/IV/2017 tanggal 6 April 2017.

\section{DAFTAR PUSTAKA}

Adhawati, S.S., 1997. Analisis Ekonomi Pemanfaatan Lahan Pertanian Dataran Tinggi di Desa Parigi (Hulu DAS Malino) Kabupaten Goa. Thesis Program Pasca Sarjana Universitas Hasanudin. Makasar.

Anonimus, 1992. Manual Kehutanan. Departemen Kehutanan Republik Indonesia. Jakarta.

Anonimus, 1999. Undang-Undang No. 41 tahun 1999 tentang Kehutanan. Pemerintah Rebublik Indonesia. Jakarta.

Asdak, C., 2004. Hidrologi dan Pengelolaan Daerah Sungai. Gadjah Mada University Press. Yogyakarta.

Azwar, S., 2010. Sikap Manusia, Teori dan Pengukurannya. Edisi ke-2. Pustaka Pelajar. Yogyakarta.

Bukhari dan Febryano, I.G., 2009. Desain Agroforestry pada Lahan Kritis (Studi Kasus di Kecamatan Indrapuri Kabupaten Aceh Besar). Jurnal Perennial, 6(1):53-59.

Dassir, M., 2008. Resolusi Konflik Pemanfaatan Lahan Masyarakat dalam Kawasan Hutan di Kabupaten Luwu Timur. Jurnal Hutan dan Masyarakat, 3(1):1-10.

Darusman, D., 1993. Pemukiman Perambah Hutan yang Berwawasan Pembangunan Wilayah. Makalah pada Diskusi Terbatas Pemukiman Masyarakat Perambah Hutan, Departemen Transmigrasi dan Pemukiman Perambah Hutan, 4 Mei 1993. Jakarta.

Dwiprabowo, H., Effendi, R., Hakim, I., dan Bangsawan, I., 2011. Kontribusi Kawasan Hutan dalam Menunjang Ketahanan Pangan: Studi Kasus Provinsi jawa Barat. Jurnal Analisis Kebijakan Kehutanan, 8(1):47-61.

Fuad, F., dan Maskanah, S., 2000. Inovasi Penyelesaian Sengketa Pengelolaan Sumber Daya Hutan. Pustaka LATIN. Bogor.

Hairiah, K., Suprayogo, D., dan Noordwijk, M.V., 2004. Ketebalan Serasah sebagai Indikator Daerah Aliran Sungai (DAS) yang Sehat. Word Agroforestry Center. Bogor.

Heryatna, D., Zainal, S., Husni, H., 2015. Persepsi Masyarakat terhadap Keberadaan Hutan Kemasyarakatan di Desa Meragun Kecamatan Nangan Taman Kabupaten Sekadau. Jurnal Hutan Lestari, 4(1):58-64.

Hidayat, S., 2012. Komposisi dan Struktur Tegakan Penghasil Kayu Bahan Bangunan di Hutan Lindung Tanjung Tiga Muara Enim Sumatera 
Selatan. J. Manusia \& Lingkungan, 22(2):194200.

Indriyanto, 2006. Ekologi Hutan. Penerbit Bumi Aksara. Jakarta.

Kaimuddin, 2008. Analisa Perambahan Kawasan Hutanterhadap Kebocoran Karbon dan Perubahan Iklim. Jurnal Hutan dan Masyarakat, 3(2):119-123.

Maring, P., 2013. Kekuasaan dan Kjonflik Sosial : Kasus Penguasaan Hutan Noge di Tanaloran Flores. Insani, 15(2):1-11.

Nair, R., 1993. An Introduction to Agroforestry. Kluver Academic Publisher-Boston in cooperative with International Centre for Research in Agroforestry.

Nazir, M., 2009. Metode Penelitian. Cetakan ke-7. Ghalia Indonesia. Bogor.

Nugraha, A., 1999. Latar Belakang Konflik Sosial di Sektor Kehutanan: Suatu Tinjauan dari Perspektif Antropolog. Makalah pada Pelatihan Upaya Pemberdayaan Masyarakat Melalui Program PMDH dan Koperasi. 28 Oktober 1999. Samarinda.

Pruitt, D.G., dan Rubin, J.Z., 2009. Teori Konflik Sosial. Pustaka Pelajar. Yogyakarta.

Purwanti, R., 1997. Pendapatan Petani Dataran Tinggi Sub DAS Malino Studi Kasus Kelurahan Gantarang Kabupaten Gowa. Jurnal Penelitian Sosial dan Ekonomi Kehutanan, 4(3):257-269

Rahmat, M., 2011. Peran Sektor Kehutanan dalam Perekonomian Kabupaten Ogan Komering Ulu Selatan. Jurnal Penelitian Sosial dan Ekonomi Kehutanan, 8 (2): 110-121.

Safitri, M.A., Muhshi, M.A., Muhajir, M., Shohibuddin, M., Arizona, Y., Sirait, M., Nagara, dan Santoso, H., 2011. Меnuju Kepastian dan Keadilan Tenurial (Edisi revisi). Epistema Institute. Jakarta:

Senoaji, G., 2009. Kontribusi Hutan Lindung terhadap Masyarakat Sekitarnya: Studi Kasus di Desa Air Lanang Bengkulu. J. Manusia \& Lingkungan, 16(1):12-22.

Senoaji, G., 2011. Perilaku Masyarakat Baduy dalam Mengelola Hutan Lahan dan Lingkungan di Banten Selatan. Humaniora, 23(1):14-25.

Senoaji, G., 2012. Pengelolaan Lahan dengan Sistem Agroforestry oleh Masyarakat Baduy di
Banten Selatan. Jurnal Bumi Lestari, 12(2):283-293.

Simon, H., 2001. Pengelolaan Hutan Bersama Rakyat (Cooperative Forest Management) Teori dan Aplikasi Pada Hutan Jati di Jawa. Bigraf Publishing. Yogyakarta.

Simon, H., 2007. Menatap ke Depan Kehutanan Indonesia dalam Membangun KPH: Keharusan untuk Hutan Indonesia Lestari. Debut Press. Yogyakarta.

Supratman, 2007. Pengembangan Usaha Masyarakat di dalam Kawasan Hutan (Studi Kasus Masyarakat Desa-Desa Sekitar Areal IUPHHK di Kabupaten Mamuju, Provinsi Sulawesi Barat). Jurnal Hutan dan Masyarakat, 2(3):303-312

Supyan, 2011. Pengembangan Daerah Konservasi sebagai Tujuan Wisata. Jurnal Mitra Bahari, 5:53-69

Sylviani dan Hakim, I., 2014. Analisis Tenurial dalam Pengembangan Kesatuan Pengelolaan Hutan (KPH) : Studi Kasus KPH Gedong Wani Provinsi Lampung. Jurnal Penelitian Sosial dan Ekonomi Hutan, 11(4):309-322.

Triwanto, J., Syarifuddin, A., Mutaqin, T., 2012. Aplikasi Agroforestry di Desa Mentaraman Kecamatan Donomulyo Kabupaten Malang. Dedikasi, 9(1):13-21.

Ulya, N.A., Warsito, S.P., Andayani, W., dan Gunawan, T., 2014. Nilai Ekonomi Air untuk Rumah Tangga dan Transportasi, Studi Kasus di Desa Desa Sekitar Hutan Rawa Gambut Merang Kepayang, Sumatera Selatan. J. Manusia \& Lingkungan, 21(2):232-238.

Wibowo, A., 2013. Kajian Penurunan Emisi Gas Rumah Kaca Sektor Kehutanan untuk Mendukung Kebijakan Perpres No. 61 tahun 2011. Jurnal Analisis Kebijakan Kehutanan, 10(3):235-254

Yusran dan Abdulah, N., 2007. Tingkat Ketergantungan Masyarakat terhadap Kawasan Hutan di Desa Borisallo Kecamatan Parangloe Kabupaten Goa Sulawesi Selatan. Jurnal Hutan dan Masyarakat, 2(1):127-135.

Zubayr, M., Darusman, D., Nugroho, B., dan Nurrohmat, D.R., 2014. Peranan dalam Pihak dalam Implementasi Kebijakan Penggunaan Kawasan Hutan untuk Pertambangan. Jurnal Analisis Kebijakan Kehutanan, 11(3):203-213. 